\title{
Prediction of seasonal climate-induced variations in global food production
}

\author{
Toshichika lizumi ${ }^{1 \star}$, Hirofumi Sakuma ${ }^{2,3}$, Masayuki Yokozawa', Jing-Jia Luo ${ }^{4}$, Andrew J. Challinor ${ }^{5,6}$, \\ Molly E. Brown ${ }^{7}$, Gen Sakurai ${ }^{1}$ and Toshio Yamagata ${ }^{3}$
}

\begin{abstract}
Consumers, including the poor in many countries, are increasingly dependent on food imports ${ }^{1}$ and are thus exposed to variations in yields, production and export prices in the major food-producing regions of the world. National governments and commercial entities are therefore paying increased attention to the cropping forecasts of important food-exporting countries as well as to their own domestic food production. Given the increased volatility of food markets and the rising incidence of climatic extremes affecting food production, food price spikes may increase in prevalence in future years ${ }^{2-4}$. Here we present a global assessment of the reliability of crop failure hindcasts for major crops at two lead times derived by linking ensemble seasonal climatic forecasts with statistical crop models. We found that moderate-to-marked yield loss over a substantial percentage (26-33\%) of the harvested area of these crops is reliably predictable if climatic forecasts are near perfect. However, only rice and wheat production are reliably predictable at three months before the harvest using within-season hindcasts. The reliabilities of estimates varied substantially by crop-rice and wheat yields were the most predictable, followed by soybean and maize. The reasons for variation in the reliability of the estimates included the differences in crop sensitivity to the climate and the technology used by the crop-producing regions. Our findings reveal that the use of seasonal climatic forecasts to predict crop failures will be useful for monitoring global food production and will encourage the adaptation of food systems to climatic extremes.
\end{abstract}

Although global crop monitoring and yield prediction models (for example, the Global Information and Early Warning System of the Food and Agriculture Organization of the United Nations ${ }^{5}$ and the Famine Early Warning Systems Network ${ }^{6}$ ) have been developed, few studies have evaluated the reliability of seasonal climatic forecast-based cropping predictions on a global scale. However, global commodity markets are essential to maintaining national food balances and affordable access for consumers, including the poor ${ }^{7,8}$. Large increases in food prices since 2008, occurring as a result of the widespread drought in cropexport regions in 2008 and 2012, coupled with a transforming food system (that is, the increasing production of biofuels) increase the importance of being able to anticipate large changes in food production ${ }^{9-11}$. These changes affect both the rural and urban poor who are reliant on imports from the global commodity market to ensure that a sufficient amount of food is available to meet demand.

We conducted a global overview of the reliability of crop failure forecasts for maize, rice, wheat and soybean, which are the principal cereal and legume crops worldwide, providing nearly $60 \%$ of all calories produced on croplands ${ }^{12}$. The key question posed was: How reliable is the forecasting of crop failure at lead times that allow such information to be of value to governments and commercial concerns? Previous work on this topic focused on predicting extreme events with either a smaller geographical focus ${ }^{13}$ or by using methods that limited their usefulness in connection to broader climate modelling efforts ${ }^{14}$.

We assessed the reliability of hindcasts (that is, retrospective forecasts for the past) of crop yield loss relative to the previous year for two lead times. Pre-season yield predictions employ climatic forecasts and have lead times of approximately 3 to 5 months for providing information regarding variations in yields for the coming cropping season (Fig. 1). Within-season yield predictions use climatic forecasts with lead times of 1-3 months. Pre-season predictions can be of value to national governments and commercial concerns, complemented by subsequent updates from within-season predictions. The latter incorporate information on the most recent climatic data for the upcoming period of reproductive growth ${ }^{15}$. In addition to such predictions, hindcasts using the reanalysed historical climatic data (that is, observations) were performed to demonstrate the upper limit of the reliability of crop forecasting.

Hindcasts using the reanalysed climatic data for the 19832006 interval indicated that the upper limits of prediction of moderate-to-marked ( $5 \%$ more) yield losses were reliably captured $\left(R^{2} \geq 0.301\right.$ when reported and hindcast yield losses were compared; $P<0.05)$ by modelling from 26 to $33 \%$ of the total crop areas harvested worldwide in 2000 (Fig. 2 and Supplementary Table S1). These areas accounted for $28-40 \%$ of the world crop production in that year. The reliability of the estimates of yield levels (including values that were approximately normal or beyond normal) when using the reanalysed climatic data was comparable to that of the estimates of crop failures mentioned above (Fig. 2 and Supplementary Information S1). If such reliability is to be realized for not only crop failures but also yield levels, both temperature and soil moisture forecasts must be near perfect.

When within-season hindcasts were evaluated, good reliability was evident in a number of areas throughout the world, including

\footnotetext{
${ }^{1}$ National Institute for Agro-Environmental Sciences, Tsukuba 305-8604, Japan, ${ }^{2}$ Research Institute for Global Change, Yokohama Institute for Earth Sciences, JAMSTEC, Yokohama 236-0001, Japan, ${ }^{3}$ Application Laboratory, Yokohama Institute for Earth Sciences, JAMSTEC, Yokohama 236-0001, Japan, ${ }^{4}$ Centre for Australian Weather and Climate Research, Bureau of Meteorology, Melbourne, Victoria 3008, Australia, ${ }^{5}$ Institute for Climate and Atmospheric Science, School of Earth and Environment, University of Leeds, Leeds LS2 9JT, UK, ${ }^{6}$ CGIAR-ESSP Program on Climate Change, Agriculture and Food Security (CCAFS), Department of Plant and Environmental Sciences, Faculty of Science, University of Copenhagen, Frederiksberg DK-1958, Denmark, ${ }^{7}$ Biospheric Sciences Branch, NASA Goddard Space Flight Center, Greenbelt, Maryland 20771, USA. *e-mail: iizumit@affrc.go.jp
} 


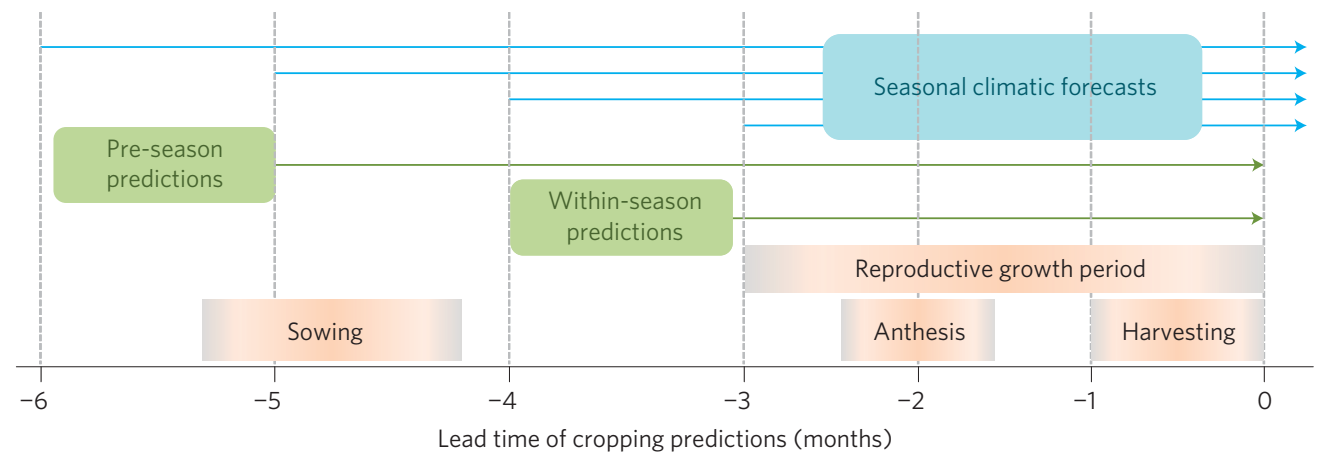

Figure 1 | Timing of cropping predictions. The cropping calendar illustrates the times at which the pre- and within-season predictions of crop failures and yield levels were conducted and the lead times of seasonal climatic forecasts on a monthly basis.

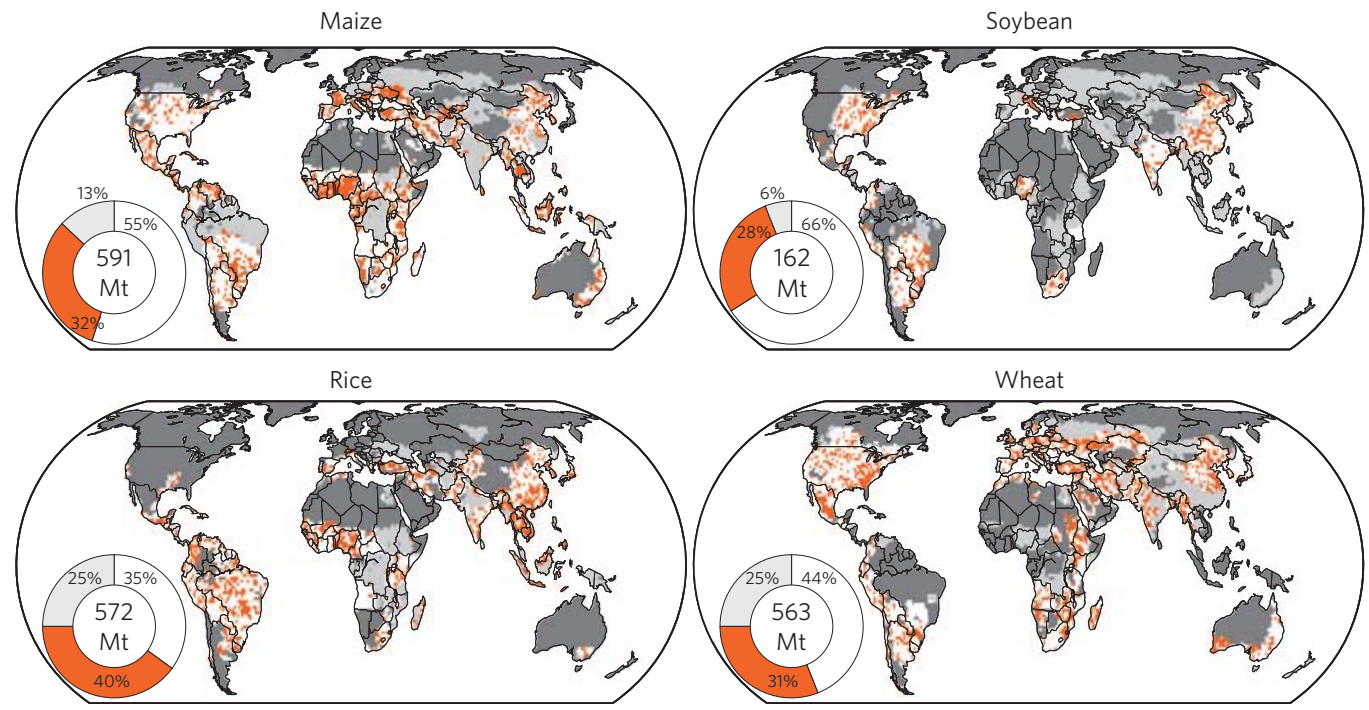

Figure $\mathbf{2}$ | The upper limits of reliability when moderate-to-marked yield losses of maize, soybean, rice and wheat were hindcasted using reanalysis data. White; yield losses were less reliably estimated (the coefficients of determination, $R^{2}$, between the reported and hindcast yields over the $1983-2006$ period $<0.454, n=10, P>0.05)$. Orange; yield losses could be reliably estimated ( $\left.R^{2} \geq 0.454, n=10, P<0.05\right)$. Light grey; no hindcast were produced because the crop calendar is lacking. Dark grey; non-cropland. The pie diagrams indicate the percentages of production from the areas. All data in the pie diagrams are normalized against the world production in 2000.

major crop-producing regions, such as Southeast Asia for rice and Australia for wheat (Fig. 3). With climatic hindcasts, the capability of modelling was more distinct when identifying the occurrences of crop failures than when predicting all of the year-to-year variations in yield levels throughout the years (Fig. 3 and Supplementary Information S2). Note, however, that reported crop yields are not always reliable over the time series used in this analysis, and the results for some countries should be interpreted with caution.

Comparatively higher reliability of pre-season hindcasts was found in areas with similar within-season hindcasts (for example, Southeast Asia for rice; Supplementary Figs S3 and S4), although such reliability gradually decreased with increasing lead time (Supplementary Table S1), as has been previously reported ${ }^{16}$. However, the ability of modelling to capture crop failures (17-21\% of total production; Supplementary Fig. S3 and Table S1) was still higher in comparison with that of predicting yield levels (5-11\% of total production; Supplementary Fig S4 and Table S1).

Of the total crop area harvested worldwide, 15-19\% (accounting for $15-23 \%$ of production) appeared to be reliable when the within-season crop failure hindcasts were evaluated (Fig. 3 and Supplementary Table S1). This result indicates that the crop failure hindcasts for all crops attained more than $50 \%$ of their predictive potential whereas yield hindcasts achieved considerably less than $36 \%$ of their potential. For both crop failures and yield levels, the hindcast values for rice and wheat, the production of which seems to be more sensitive to temperature than to soil moisture content (Fig. 4), were better at both lead times than the values obtained from the random hindcasts (the comparisons were significant at the $1 \%$ level and Supplementary Fig. S5). In contrast, the hindcast values for maize and soybean conducted at both lead times (the production of which is more sensitive to soil moisture content than to temperature; Fig. 4) were not significantly better than the random hindcast values (Supplementary Fig. S5).

The observed spread in hindcast yield reliability across different crop types reflects the finding that temperature hindcasts are far more reliable than predictions of soil moisture content at both lead times (Supplementary Figs S6 and S7). Higher hindcast temperature reliability plays a certain role with respect to gains in the reliability of within-season cropping hindcasts in irrigated cropland, which covers approximately $20 \%$ of cultivated land and accounts for over $40 \%$ of world production ${ }^{17}$, although more land area is rainfed (Supplementary Fig. S8). This tendency is particularly true in irrigated areas where yields are sensitive to temperature, probably because temperature is a major driver of yield variations if a crop is irrigated sufficiently, whereas the soil moisture content is still important under insufficient irrigation conditions, as suggested by a previous study ${ }^{18}$.

In addition, the hindcast climatic reliability was higher when data from low latitudes were evaluated rather than those from 


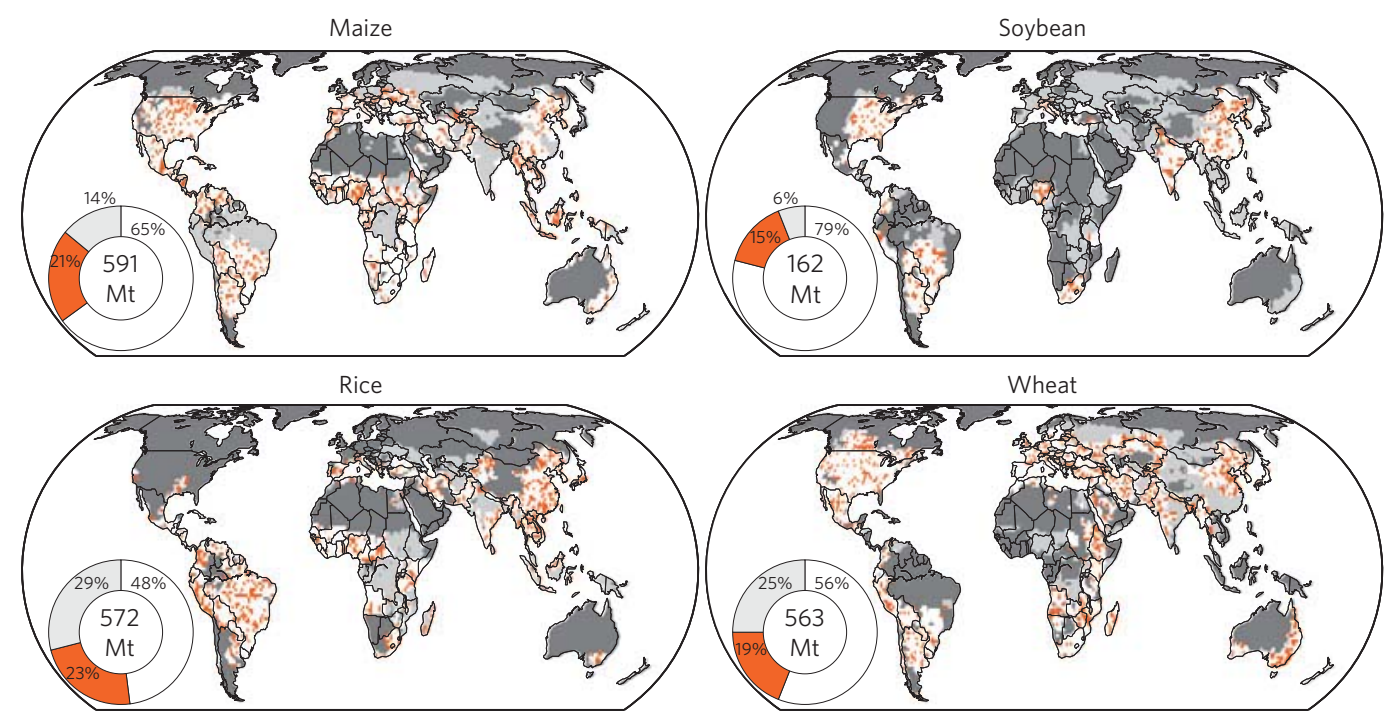

Figure 3 | The reliability of the within-season hindcasts of the moderate-to-marked ( $5 \%$ more) yield losses for maize, soybean, rice and wheat. The legend for Fig. 2 is also applicable to this figure, although the within-season (and not the pre-season) hindcasts were derived. $R^{2}<0.301$ and $R^{2} \geq 0.301$ (both, $n=10, P<0.05$ ) were used for the areas in white and orange, respectively.
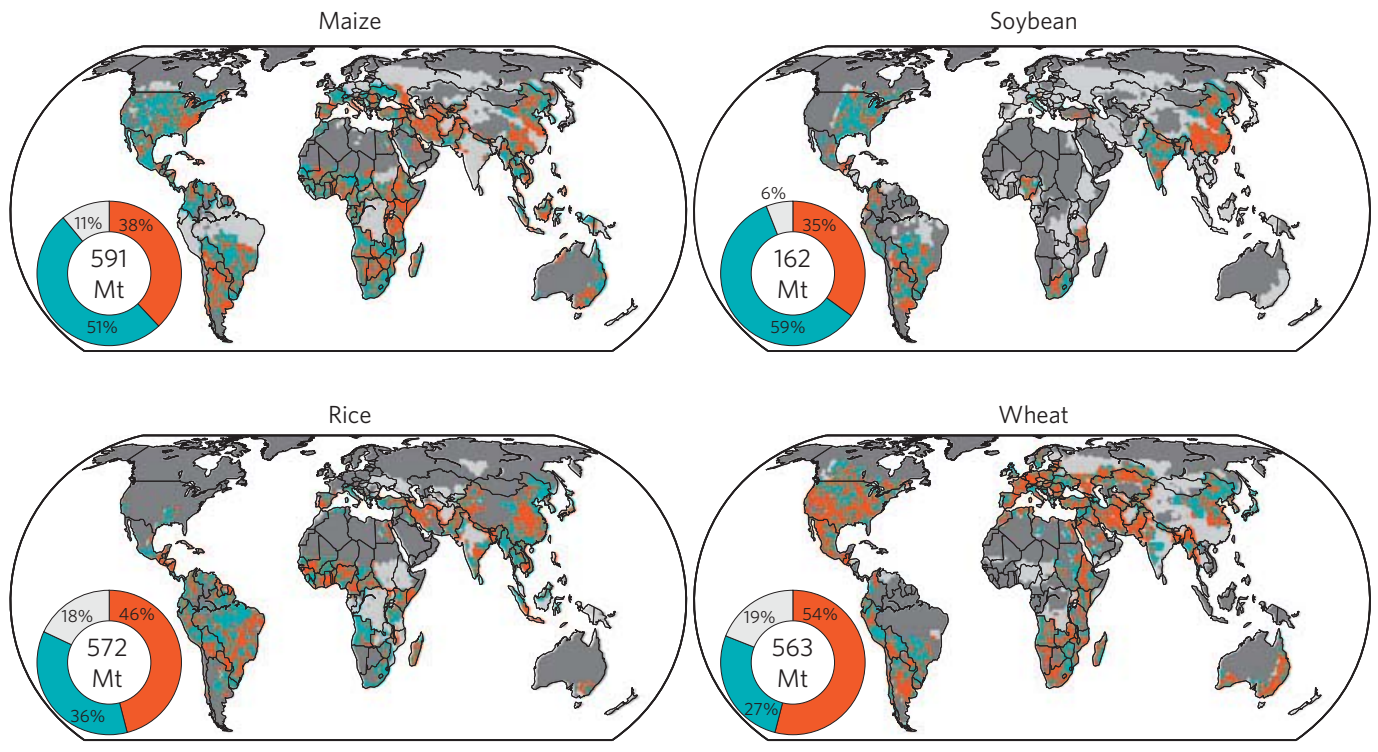

Figure 4 | The dominant climatic factors affecting the year-to-year variations in the yields of maize, soybean, rice and wheat. The pie diagrams indicate the percentages of production that are sensitive to temperature (orange) and soil moisture content (turquoise) as well as those for which no hindcasts were available (grey) in 2000. The dark grey area indicates non-cropland.

the mid-to-high latitudes (Supplementary Figs S6 and S7); this conclusion is similar to that obtained in earlier studies ${ }^{19}$. Of the top four countries in terms of maize and soybean production (the USA, Brazil, China and Argentina), all but Brazil are located at mid-latitudes, whereas rice is widely produced (particularly in the tropics) and wheat is grown more extensively worldwide than any other crop (Supplementary Fig. S9 and Table S1). For wheat in particular, the timing of the growing season is important: a large proportion of wheat is grown in winter. Winter climate forecasts in the Northern Hemisphere are typically more accurate than summer forecasts because the extratropical winter atmosphere is strongly influenced by events in tropical regions and because the effects of tropical climatic variations on winter climatic patterns in the Northern Hemisphere are stronger than on that of the summer ${ }^{20}$. Owing to differences in the characteristics of production systems, the reliability of the estimates of rice and wheat yield losses was highest, distantly followed by those of soybean and maize (Supplementary Fig. S5 and Table S1). For the estimates of yield levels, wheat prediction was most reliable, followed by the estimates of rice, soybean and maize (Supplementary Table S1).

The relatively high reliability of hindcasts to capture the crop failures of rice and wheat and to predict the year-to-year variations in wheat yield levels in particular encouraged us to extract further information. The areas for which within-season hindcasts of yield levels are available include four of the major wheat-exporting countries, namely, the USA, France, Canada and Australia. Together, these regions produced 53\% of the world wheat export in 2008 (Supplementary Fig. S10). In these areas, withinseason hindcasts were reliable for $9 \%$ to $35 \%$ of the harvested area (Fig. 5), suggesting that up to $11 \%$ of all wheat exports from these four countries are predictable $(27 \%$ of world wheat exports were predictable when the data from all wheat-exporting countries were considered; Supplementary Table S1). When the pre-season yield 

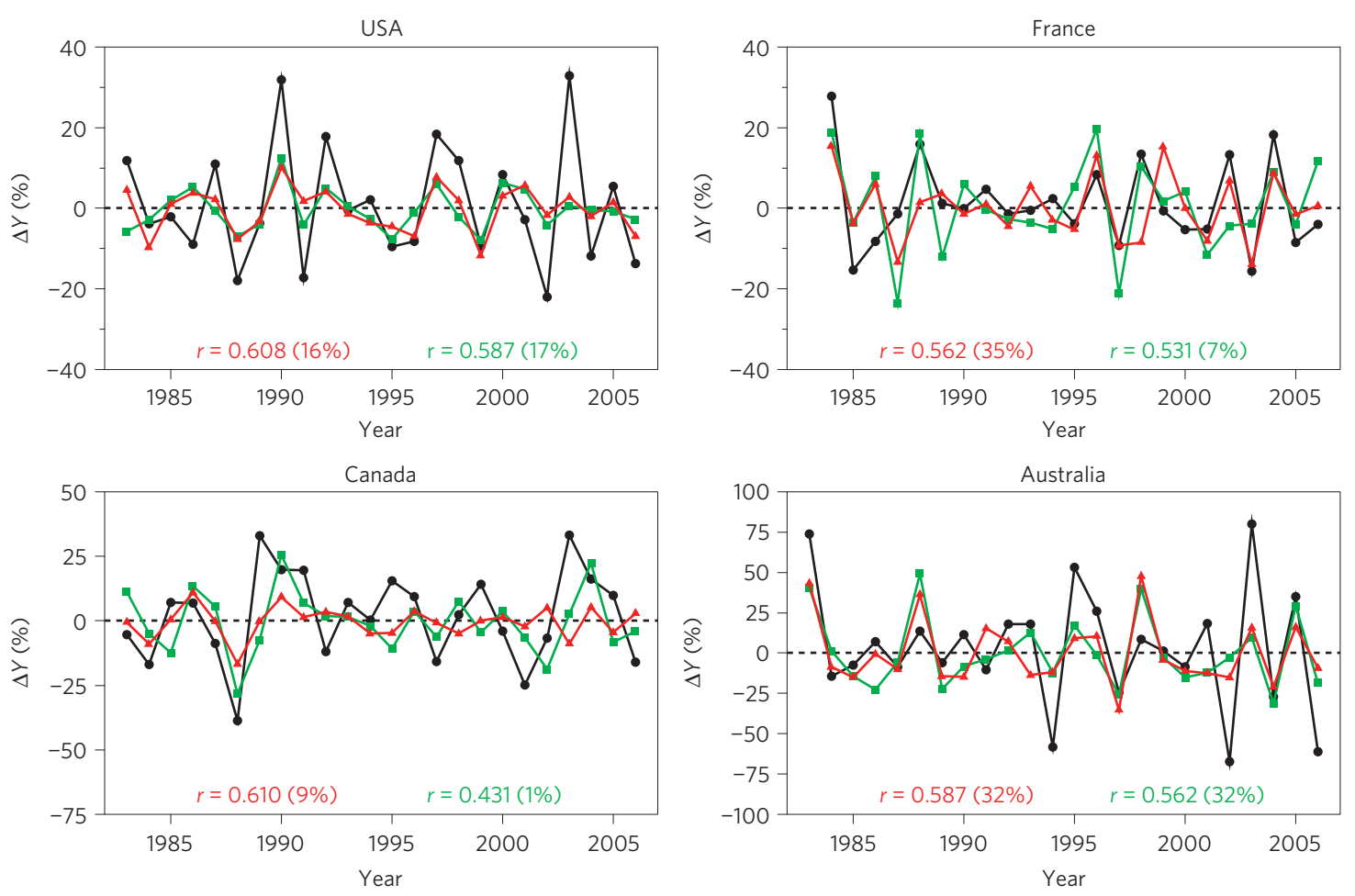

Figure 5 | The capture reliability of the year-to-year relative wheat yield variations $(\Delta Y)$ for the reliable areas in four major wheat-exporting countries (the USA, France, Canada and Australia). The reported yields (black), pre-season hindcasts (green) and within-season hindcasts (red) are presented. The $r$ values are correlation coefficients, which were calculated by comparing the reported values with that obtained from the two hindcasts. All correlations were significant at the $5 \%$ level. The numbers in parentheses are the percentages of areas for which yields were reliably predictable among all of the harvested areas within each country.

hindcasts were evaluated, the area for which the predictions were reliable was lower (1-32\% of all harvested areas in the exporting countries mentioned above; Fig. 5); however, the reliability level was similar to that afforded by the analysis of within-season hindcasts from the USA and Australia.

In contrast, the levels of rice exports that were reliably predicted were far lower than those of wheat exports when the yield hindcasts were evaluated but were comparable when the crop failure hindcasts were assessed (Supplementary Table S1). Notably, a considerable extent of the predictable area $(52-78 \%$ of the national harvested area) was found in the third major rice exporter, Uruguay (Supplementary Fig. S11). The second-major rice exporter, Thailand, exhibited even less predictable area $(3 \%$ of the national harvested area); although Thailand is located in the tropics, this result is probably due to the lack of crop calendar data for the triple cropping systems under operation in that region ${ }^{21}$ (T.I. et al. manuscript in preparation) and the higher sensitivity of yields to soil moisture conditions (Fig. 4).

We found that the principal features of climate-induced crop failures in a substantial percentage of the global crop-growing regions were reliably predictable for rice and wheat but were less predictable for maize and soybean. The particular features of global production systems allow reliable estimates of crop failure, including a notable association between crop yields and ambient temperature, an extensive growth area worldwide (or within the tropics), significant production from winter cropping, and accurate estimates of winter temperatures. Notably, the areas within which the occurrences of crop failures (or yield levels) are reliably predictable include the countries that are major exporters of wheat and rice. This finding suggests that modelling can potentially yield information on the seasonal climate-induced variability in the production levels of rice and wheat in major exporter countries and that such estimates can be made available 3-5 months before harvest. Such information would be of value to both national governments and commercial entities for maintaining an adequate national food balance and ensuring adequate responses to major food crises. These data, when combined with satellitederived information on rainfall levels and the extent of vegetative productivity $^{22}$, can support a range of decisions, including the adaptation of food systems for the poor to climatic extremes and, ultimately, to climate change.

However, considerable work is required to produce operational forecasts because yield levels do not exclusively determine the extent to which food is supplied to commodity markets and prices. Sociopolitical factors (that is, the Russian wheat embargo of 2010-201123) often critically influence the world food supply and are often motivated by crop failures induced by climatic extremes. Decision-makers struggle to respond within a timely manner if predictions remain uncertain for even a few months of lead ${ }^{24}$.

The predictions derived from the modelling presented here or from more plant physiological process-based crop models of this type ${ }^{16,25,26}$ can be used to establish a global crop failure prediction system. Although process-based models may be promising at specific sites ${ }^{16}$, there is a lack of global historical crop data sets, which would be required for more sophisticated representations of hybrid seeds, planting dates, and nitrogen, water and chemical inputs. Furthermore, the methods of climate impact assessment have tended to use yield variability as a measure of uncertainty, instead of assessing changes in crop yield variability ${ }^{27}$. We demonstrate the potential for skilful predictions of crop failures, which in turn suggest that the limitation of qualitative methods can be addressed. In demonstrating the potential value of quantitative prediction methods, this study also supports evidence ${ }^{28}$ for the potential use of such methods in regions where qualitative methods dominate at present, for example, sub-Saharan Africa ${ }^{13}$. 


\section{Methods}

Climate and crop data for the 1982-2006 interval were collected by using a grid with a resolution of $1.125^{\circ}$ in both latitude and longitude. The temperature and soil moisture data were downloaded from the JRA-25 monthly reanalysed data set ${ }^{29}$. For each of the four crops, all reanalysed data were averaged over the reproductive growth periods, as determined from the global crop calendar data set ${ }^{21}$. Thus, the climatic features specific to individual locations, over the months of crop growth, were considered.

Nine ensemble seasonal climatic hindcasts (three physically perturbed models, for which three sets each of initial conditions were used) were generated by using the SINTEX-F ocean/atmosphere-coupled general circulation model; the prediction lead times ranged from 1 to 12 months $^{20}$. The lead data for 1-3 and $3-5$ months were averaged to yield the within-season and pre-season hindcasts, respectively. Biases in the global climate model predictions for temperature and soil moisture were removed before analysis.

Crop yields were obtained from the global historical yield data set (T.I. et al. manuscript in preparation), which aligns the FAO yield data and grid yield proxy information derived from satellite-derived net primary productivity.

The crop and climate data were combined as follows: a first-difference time series was computed by using the yield levels and a reanalysis of the temperature and soil moisture data; each first-difference yield was divided by the 3-year average of the yield to derive the percentage first-difference values; a multiple linear regression model was constructed for each cropping system; weighted-average yields were calculated by using the production levels by cropping system as weighting factors; regression coefficients were determined on a year-by-year basis by using the leave-one-out cross-validation method; finally, all bias-corrected climatic forecasts were subjected to regression modelling to derive the hindcast data (the percentage changes in yield from that of the previous year).

\section{Received 10 December 2012; accepted 4 June 2013;} published online 21 July 2013

\section{References}

1. The State of Food Insecurity in The World: How Does International Price Volatility Affect Domestic Economies and Food Security? (FAO, 2011).

2. Funk, C. C. \& Brown, M. E. Declining global per capita agricultural production and warming oceans threaten food security. Food Sec. 1, 271-289 (2009).

3. Report of the FAO Expert Meeting on How to Feed the World in 2050 (FAO, 2009).

4. IPCC Managing the Risks of Extreme Events and Disasters to Advance Climate Change Adaptation (Cambridge Univ. Press, 2012).

5. Global Information and Early Warning System on Food and Agriculture (FAO, 2013); available at http://www.fao.org/giews/english/index.htm

6. Famine Early Warning System Network (FEWS, 2012); available at http://www.fews.net/Pages/default.aspx

7. Ravallion, M., Chen, S. \& Sangraula, P. New Evidence on the Urbanization of Global Poverty (World Bank, 2007).

8. Ruel, M. T., Garrett, J. L., Hawkes, C. \& Cohen, M. J. The food, fuel, and financial crises affect the urban and rural poor disproportionately: A review of the evidence. J. Nutr. 140, 170S-176S (2010).

9. Rosegrant, M. W., Msangi, S., Sulser, T. \& Valmonte-Santos, R. Biofuels and the Global Food Balance. 2020 Vision for Food, Agriculture and the Environment (International Food Policy Research Institute, 2006).

10. Headey, D. \& Fan, S. Anatomy of a crisis: The causes and consequences of surging food prices. Agric. Econ. 39, 375-391 (2008).

11. Stringer, L. C. et al. Adaptations to climate change, drought and desertification: Local insights to enhance policy in southern Africa. Environ. Sci. Policy 12, 748-765 (2009).

12. Ray, D. K., Ramankutty, N., Mueller, N. D., West, P. C. \& Foley, J. A. Recent patterns of crop yield growth and stagnation. Nature Commun. 3, 1293 (2012).

13. Hansen, J. W., Mason, S. J., Sun, L. \& Tall, A. Review of seasonal climate forecasting for agriculture in sub-Saharan Africa. Exp. Agric. 47, 205-240 (2011)
14. Lenton, T. M. What early warning systems are there for environmental shocks? Environ. Sci. Policy 24, S60-S75 (2012).

15. Cane, M. A., Eshel, G. \& Buckland, R. W. Forecasting Zimbabwean maize yield using eastern equatorial Pacific sea surface temperature. Nature 370, 204-205 (1994).

16. Hansen, J. W., Challinor, A. J., Ines, A. V. M., Wheeler, T. R. \& Moron, V. Translating climate forecasts into agricultural terms: Advances and challenges. Clim. Res. 33, 27-41 (2006).

17. World Water Assessment Programme The United Nations World Water Development Report 4: Managing Water under Uncertainty and Risk (United Nations Educational, Scientific and Cultural Organization, 2012).

18. Hawkins, E. et al. Increasing influence of heat stress on French maize yields from the 1960s to the 2030s. Glob. Change Biol. 19, 937-947 (2013).

19. Wilks, D. S. \& Godfrey, C. M. Diagnostic verification of the IRI net assessment forecasts, 1997-2000. J. Clim. 15, 1369-1377 (2002).

20. Luo, J-J., Masson, S., Behera, S., Shingu, S. \& Yamagata, T. Seasonal climate predictability in a coupled OAGCM using a different approach for ensemble forecasts. J. Clim. 18, 4474-4497 (2005).

21. Sacks, W. J., Deryng, D., Foley, J. A. \& Ramankutty, N. Crop planting dates: An analysis of global patterns. Glob. Ecol. Biogeogr. 19, 607-620 (2010).

22. Funk, C. New satellite observations and rainfall forecasts help provide earlier warning of drought in Africa. Earth Observer. 21, 23-27 (2009).

23. Welton, G. The Impact of Russia's 2010 Grain Export Ban (Oxfam, 2011); available at http://www.oxfam.org/sites/www.oxfam.org/files/ rr-impact-russias-grain-export-ban-280611-en.pdf

24. Vogel, C. \& O'Brien, K. Who can eat information? Examining the effectiveness of seasonal climate forecasts and regional climate-risk management strategies. Clim. Res. 33, 111-122 (2006).

25. Challinor, A. J., Ewert, F., Arnold, S., Simelton, E. \& Fraser, E. Crops and climate change: Progress, trends, and challenges in simulating impacts and informing adaptation. J. Exp. Bot. 60, 2775-2789 (2009).

26. Iizumi, T., Yokozawa, M. \& Nishimori, M. Parameter estimation and uncertainty analysis of a large-scale crop model for paddy rice: Application of a Bayesian approach. Agr. For. Meteorol. 149, 333-348 (2009).

27. Easterling, W. E. et al. in IPCC Climate Change 2007: Impacts, Adaptation and Vulnerability (eds Parry, M. L. et al.) Ch. 5 (Cambridge Univ. Press, 2007).

28. Vermeulen, S. J. et al. Addressing uncertainty in adaptation planning for agriculture. Proc. Natl Acad. Sci. USA 110, 8357-8362 (2013).

29. Onogi, K. et al. The JRA-25 Reanalysis. J. Meteorol. Soc. Jpn 85, 369-432 (2007).

\section{Acknowledgements}

We thank R. C. Stone, P. McIntosh, H. Kanamaru and M. Otsuka for helpful comments on the earlier version of this manuscript. T.I. was supported by the Japan Society for the Promotion of Science (JSPS) Grant-in-Aid for Research Activity Start-up (23880030). T.I, M.Y. and G.S. were supported by the Environment Research and Technology Development Fund (S-10-2) of the Ministry of the Environment, Japan. The Science and Innovation Section of the British Embassy in Tokyo provided us with the opportunity to conduct this study through a UK-Japan workshop arrangement.

\section{Author contributions}

T.I. was responsible for the study design, data analysis and manuscript preparation. J-J.L. contributed seasonal climatic forecasting and assisted in manuscript preparation. G.S. provided the computational code used to optimize the crop yield modelling. H.S., M.Y., A.J.C., M.E.B and T.Y. assisted with the study design and helped write the manuscript.

\section{Additional information}

Supplementary information is available in the online version of the paper. Reprints and permissions information is available online at www.nature.com/reprints. Correspondence and requests for materials should be addressed to T.I.

\section{Competing financial interests}

The authors declare no competing financial interests. 